\title{
Assistência de Enfermagem frente a parada cardiorrespiratória no setor da emergência: Um relato de experiência
}

Nursing care in the face of cardiorespiratory arrest in the emergency sector: An experience report

La atención de enfermería ante la parada cardiorrespiratoria en el sector de urgencias: Un relato de experiencia

Gisele Gomes Dourado ORCID: https://orcid.org/0000-0003-3282-4015 Faculdade Irecê, Brasil E-mail: gisele97dourado@gmail.com

Jaciara Mendes Cardoso ORCID: https://orcid.org/0000-0002-6915-9090 Faculdade Irecê, Brasil

E-mail: ciarajaci@hotmail.com

Larissa Reis Almeida ORCID: https://orcid.org/0000-0002-5498-8857 Faculdade Irecê, Brasil

E-mail: larissaenf4@gmail.com

Iago Araújo Duarte

ORCID: https://orcid.org/0000-0002-8192-6977 Faculdade Irecê, Brasil

E-mail: Iago23araujo@gmail.com Iandra Gabriela De Almeida Matos ORCID: https://orcid.org/0000-0002-7794-024X Faculdade Irecê, Brasil

E-mail: iandragabriela@hotmail.com

Jaciara Profiro Barbosa

ORCID: https://orcid.org/0000-0002-0158-5093 Faculdade Irecê, Brasil

E-mail: jaciara_kit@hotmail.com

Marina Matos de Oliveira ORCID: https://orcid.org/0000-0003-1350-4577 Faculdade Irecê, Brasil

E-mail: marinamatosoliveira@hotmail.com

Leonardo Mendes Araújo da Silva ORCID: https://orcid.org/0000-0003-0234-7713 Faculdade Irecê, Brasil

E-mail: leoaraujomendes@hotmail.com

Tiago Patricio de Almeida Carvalho ORCID: https://orcid.org/0000-0001-8230-112X Faculdade Irecê, Brasil

E-mail: thiagow.carvalho@hotmail.com

\section{Resumo}

Objetivo: A Parada Cardiorrespiratória (PCR) é uma cessação abrupta da função cardíaca, respiratória e cerebral, nesse sentindo o trabalho tem como objetivo mostrar a importância da assistência de enfermagem frente à Parada Cardiorrespiratória (PCR), além disso, as principais ações assistenciais de enfermagem ao paciente vítima de PCR em uma unidade hospitalar em um município do interior da Bahia. Método: Trata-se de um estudo de natureza descritiva tipo relato de experiência acerca da vivência no Estágio Supervisionado II, sobre a atuação do Enfermeiro durante a parada cardiorrespiratória no município de Irecê-BA. Resultados: Nesse sentido, foi possível observar a atuação do enfermeiro na assistência de enfermagem frente a parada cardiorrespiratória, também foi possível mostrar que o enfermeiro, por meio de seus cuidados prestados, é um profissional essencial e capacitado para diagnosticar e atender uma PCR, tanto na tomada de decisões para iniciar o atendimento, quanto nos cuidados com medicação. Conclusão: O enfermeiro é de suma importância diante de uma PCR, como um profissional atuante na tomada de decisões e apto para identificar e realizar os procedimentos necessários para aumentar a sobrevida do paciente.

Palavra-chave: Parada cardiorrespiratória; Assistência de enfermagem; Ressuscitação cardiopulmonar. 


\begin{abstract}
Objective: Cardiopulmonary Arrest (CPA) is an abrupt cessation of cardiac, respiratory and brain function, in this sense, the work aims to show the importance of nursing care in front of Cardiopulmonary Arrest (CPA), in addition to the main care actions of nursing to the patient victim of CPA in a hospital unit in a city in the interior of Bahia. Method: This is a descriptive study of an experience report type about the experience in Supervised Internship II, on the role of nurses during cardiac arrest in the city of Irecê-BA. Results: In this sense, it was possible to observe the role of nurses in nursing care in the face of cardiorespiratory arrest, it was also possible to show that the nurse, through their care, is an essential and capable professional to diagnose and attend to CPA, both in decision-making to start care, as in medication care. Conclusion: The nurse is of paramount importance in the face of a CPA, as a professional active in decision-making and able to identify and carry out the necessary procedures to increase patient survival.
\end{abstract}

Keyword: Cardiopulmonary arrest; Nursing Care; Cardiopulmonary resuscitation.

\title{
Resumen
}

Objetivo: La Parada Cardiopulmonar (APC) es un cese brusco de la función cardíaca, respiratoria y cerebral, en este sentido, el trabajo tiene como objetivo mostrar la importancia del cuidado de enfermería frente al Paro Cardiopulmonar (APC), además de las principales acciones asistenciales de Enfermería al paciente víctima de CPA en una unidad hospitalaria de una ciudad del interior de Bahía. Método: Se trata de un estudio descriptivo de tipo relato de experiencia sobre la experiencia en Pasantía Supervisada II, sobre el rol del enfermero durante la parada cardíaca en la ciudad de Irece-BA. Resultados: En este sentido, se pudo observar el rol del enfermero en el cuidado de enfermería ante el paro cardiorrespiratorio, también se pudo demostrar que el enfermero, a través de su cuidado, es un profesional imprescindible y capacitado para diagnosticar y atender CPA, tanto en la toma de decisiones para iniciar la atención, como en la atención de medicamentos. Conclusión: El enfermero es de suma importancia ante el CPA, como profesional activo en la toma de decisiones y capaz de identificar y realizar los procedimientos necesarios para incrementar la supervivencia del paciente.

Palabras clave: Paro cardiopulmonar; Atención de enfermería; Reanimación cardiopulmonar.

\section{Introdução}

A Parada cardiorrespiratória (PCR) é considerada como um problema de saúde pública em todo mundo, apesar dos avanços ocorridos nos últimos anos em relação à prevenção e tratamento, muitas são as vidas perdidas anualmente no Brasil relacionadas à PCR, porém ainda não se tem a exata dimensão do problema, pela falta de estatísticas.

No entanto existe uma estimativa que ocorra cerca de 200.000 PCR ao ano no Brasil, onde cerca de $50 \%$ dos casos acontecem em ambiente hospitalar e outra metade em ambiente extra hospitalar. As PCR que ocorrem no hospital em decorrência de atividade elétrica sem pulso e a assistolia respondem pela maioria dos casos (Gonzalez et al, 2013).

Nesse sentindo a PCR é considerada como uma das mais graves emergência cardiovasculares, de grande prevalência e de elevada morbimortalidade no Brasil, sendo caracterizada como uma alteração súbita e inesperada de deficiência absoluta de oxigenação tissular seja por ineficiência circulatória ou por cessação da atividade respiratória. (Espindola, 2017; Silva, 2016).

Dessa maneira quando ocorre a PCR há um risco de danos celulares irreparáveis e lesões cerebrais graves e irreversíveis causadas pela ausência de consciência, pulso central, apneia e presença de pupilas midriáticas contudo o tempo é algo crucial pois acredita-se que a cada minuto em que a vítima fica sem ressuscitação cardiopulmonar, ocorra $10 \%$ de probabilidade de reverter a situação fica relativamente reduzida, contudo existe uma estimativa de sobrevida em torno de $70 \%$ (Prestes, 2017; Braga, 2018).

Nessa perspectiva o atendimento deve acontecer entre quatro a seis minutos, para que possa ser evitado danos neurológicos ao paciente, contudo o sucesso do resultado do atendimento da PCR está ligado diretamente com a rapidez, destreza e a qualidade de atendimento promovido pela equipe e aos avanços tecnológicos e científicos que estão cada vez mais avançados na área (Aragão et al., 2017).

Contudo se torna essencial que todos os profissionais da área de saúde, independentemente da sua especialização possuam conhecimentos para o atendimento diante de uma parada cardiorrespiratória, visto que o diagnostico rápido e preciso se tornam uma das garantias para o sucesso da RCP.

Diante disso, se torna fundamental que as equipes que trabalham em unidades de urgência e emergência tenham treinamentos para utilização dos protocolos de RCP assim como ocorra a promoção de educações continuadas, possibilitando 
dessa maneira uma maior autonomia aos profissionais envolvidos, garantindo assim condições ideais para o atendimento, norteando a assistência e organizando a forma de trabalho da equipe (Castanheira et al., 2020).

$\mathrm{Na}$ maioria das vezes, a equipe de enfermagem se encontra na linha de frente, comø isso esses profissionais devem estar atentos para reconhecer facilmente a evolução do paciente para uma parada cardiorrespiratória e dessa forma obter sucesso no atendimento. Sendo assim esses profissionais devem estar aptos a acionar a equipe para o processo de reanimação cardiopulmonar. Então cabe ao enfermeiro conhecer as patologias e suas características bem como buscar o aperfeiçoamento técnico-científico e o fortalecimento do trabalho em equipe (Rocha et al., 2012).

Dessa forma, esse estudo objetiva-se descrever a experiência vivenciada enquanto acadêmica de enfermagem, acerca da assistência de enfermagem frente a parada cardiorrespiratória no setor da emergência em um hospital do município de IrecêBahia.

\section{Metodologia}

Trata-se de estudo descritivo com abordagem qualitativa a modalidade tipo relato de experiência_onde é considerado um estudo metodológico que descreve as práticas vivenciadas pelo autor (Gil, 2010) acerca da vivência no Estágio Curricular Supervisionado II do curso de Bacharelado em Enfermagem da Faculdade Irecê-FAI. O local do estágio ocorreu em um Hospital no setor da Emergência Adulto localizada no município de Irecê-Bahia, que ocorreram entre os dias 11/08/2021 a $21 / 10 / 2021$.

Os locais de coleta dos dados foram através da Biblioteca Virtual de Saúde (BVS) e a base de dados da Scielo (ScientificElectronic Library Online). Os descritores utilizados nas consultas foram: Parada Cardíaca, Assistência de Enfermagem, Assistência Hospitalar, também foi utilizado operador booleano AND.

As bibliografias selecionadas possuem publicação entre os anos de_2010 a 2021_Os critérios de inclusão foram artigos, monografias, teses em português e inglês, disponíveis na íntegra nos bancos de dados gratuitamente. E como critérios de exclusão, os trabalhos que não respondem aos questionamentos e objetivos da pesquisa e materiais duplicados nas respectivas bases de dados.

\section{Resultados e Discussão}

Contudo o reconhecimento da parada cardiorrespiratória acontece pela detecção precoce dos principais sinais clínicos que são inconsciência, ausência de movimentos respiratórios ou gasping, nenhum pulso definido sentido em 10 segundos, cianose, lividez e dilatação pupilar (midríase), são sinais comumente utilizados na constatação da PCR. Diante disso são sinais de gravidade onde o paciente pode evoluir para uma PCR, dor torácica, sudorese, palpitações precordiais, tontura, escurecimento visual, perda de consciência, alterações neurológicas, sinais de débito cardíaco diminuído (Cruz \& Aguiar, 2018).

Ainda nessa perspectiva aponta-se que a PCR pode ser resultante de diversas patologias e situações clínicas, podendo estar associada a infarto agudo do miocárdio, obstrução de vias aéreas, hemorragia intensa, abuso de drogas ilícitas, intoxicação por gases tóxicos, arritmias cardíacas, episódio de obstrução das artérias coronárias ou a um evento terminal adjacente de outras enfermidades (Oliveira et al., 2021).

Em vista disso o atendimento dessas emergências se baseia em protocolos que seguem uma sequência lógica e baseadas em condutas para melhorar as taxas de reversibilidade do processo que desencadeou a PCR, diante disso os atendimentos são prestados a partir de dois tipos de suporte: o Suporte Básico de Vida e o Suporte Avançado de Vida.

Nesse sentido o Suporte Básico de Vida (SBV) conforme a AHA (2015), consiste em ações que devem ser executado a partir da suspeita da PCR, que envolvem a identificação rápida dos sinais clínicos, acionamento da equipe de emergência, 
iniciar as compressões torácica eficientes, seguida da abertura das vias aéreas, ventilação e por fim desfibrilação (Bernoche $e t$ al., 2019).

Nas manobras de Suporte Avançado de Vida (SAV) além de envolverem todas as acima descritas, ainda é realizado a monitorização cardíaca, o uso de dispositivos invasivos para abertura de vias aéreas, terapia medicamentosa. Além disso é composto pelo CABD secundário, que consiste na avaliação das vias aéreas e se necessário o manejo de via aérea avançada (A), ventilação avançada (B), circulação avançada (C) e diagnóstico diferencial e o tratamento das causas reversíveis da PCR (Bernoche et al., 2019).

Durante o período de estágio supervisionado foi possível presenciar 3 paradas cardiorrespiratória no setor da emergência, sendo 2 na sala vermelha e uma na sala amarela, 2 pacientes eram do sexo masculino e 1 do sexo feminino, onde foi possível observar e participar da RCP.

Portanto, durante as PCR, presenciadas durante o estágio, tivemos a oportunidade de observar as condutas iniciais frente a uma parada cardiorrespiratória, onde deve ser checado a responsividade do paciente, em seguida checar respiração e pulso simultaneamente, constatada a ausência dos mesmos, deve ser iniciado as compressões cardícas, rebaixando o tórax do paciente entre 5 a 6 cm_e deve haver o acionamento do médico (Nascer et al., 2015).

Essa reanimação cardiopulmonar (RCP) pode ser definida como o conjunto de manobras realizadas após o início de PCR com o objetivo de manter artificialmente o fluxo arterial ao cérebro e a outros órgãos vitais, até que consiga o retorno da circulação espontânea. Nesse sentido as manobras de RCP faz-se na melhor chance de restauração da função cardiopulmonar e cerebral das vítimas de PCR, em seguida se dá início as ventilações através da bolsa válvula mascara, realizando dessa forma 30 compressões cardíacas efetivas para cada 2 ventilações (Nascer et al., 2015).

Nessa perspectiva, se inicia as administrações das drogas intravenosa (IV), a primeira droga de escolha a ser administrada é Adrenalina, que pode ser usada em qualquer ritmo da PCR, onde vai ser administrado $1 \mathrm{mg}$ IV em bolus, seguido de $20 \mathrm{ml}$ de solução salina a $0,9 \%$ e elevando o membro em seguida, repetindo sua administração a cada 3 a 5 minutos. A segunda droga utilizada vai ser a amiodarona onde a 1 dose é de $300 \mathrm{mg}$ administrada IV, em bolus seguida de 20 $\mathrm{ml}$ de solução salina a $0,9 \%$, a segunda dose será de $150 \mathrm{mg}$ seguindo as mesmas recomendações de administração da primeira, no entanto a amiodarona só pode ser utilizada em ritmos FV/TVSP (Espindola et al., 2017).

Desse modo o enfermeiro, possui um papel importantíssimo diante de uma PCR, pois ele é responsável por providenciar recursos materiais, dar suporte à equipe, oferecer educação continuada e treinamentos, e principalmente, permitindo melhora na qualidade dos serviços prestados. A falta de treinamento da equipe pode ter como consequência a falta de conhecimento e preparo durante o atendimento a PCR.

Contudo_durante as PCR presenciadas, foi possível ver os_ritmos de assistolia ausência de atividade elétrica, atividade elétrica sem pulso (AESP), tem como características a ausência de pulso detectável na presença de algum tipo de atividade elétrica, a fibrilação ventricular (FV) vai ocorrer uma atividade elétrica desorganizada e taquicardia ventricular (TV) sem pulso é caracterizada como uma sequência rápida batimentos, sem pulso arterial palpável (Farias et al., 2015).

Nesse sentido a identificação do ritmo cardíaco vai ocorrer através das pás do desfibrilador ou monitor cardíaco, com a identificação do ritmo cardíaco, quando identificado a FV/TV sem pulso, o seu tratamento inicial é a desfibrilação com choque imediato na energia máxima do aparelho (360J, monofásico ou 180 a 200J, bifásico) (Farias et al., 2015).

Dessa maneira também se é discutido sobre as possíveis causas de PCR, que podem ser reversíveis que são chamadas de $5 \mathrm{H}$, hipovolemia, hipóxia, hipocalemia, hipercalemia, hipotermia, $\mathrm{H}+$ (acidose), e os $5 \mathrm{~T}$ tromboembolismo pulmonar, tamponamento cardíaco, tóxicas, tensão no tórax (pneumotórax) e trombose coronariana, muitas vezes existe uma despreocupação com a causa da RCP o que pode levar ao aumento da mortalidade, por isso em qualquer dos ritmos deve-se estar atento a correções das possíveis causas reversíveis (Aragão et al., 2017). 
Diante disso o enfermeiro possui um papel fundamental por meio de seus cuidados prestados, ele é um profissional essencial e capacitado para diagnosticar e atender uma parada cardiorrespiratória, realizando uma boa sistematização da assistência de enfermagem. Assim, foi_possível perceber a importância da atuação da equipe de enfermagem frente a uma parada cardiorrespiratória.

\section{Conclusão}

Concluir-se por tanto que a equipe de enfermagem precisa saber lidar com paciente em momentos críticos e estar bem preparado, reconhecer a PCR por meio de identificação rápida de sinais e sintomas, além de agir na tomada de decisões para iniciar o atendimento, nesse sentido a atuação da equipe de enfermagem durante a PCR é essencial, já que a equipe devem estar habilitados e ter competência para identificar a PCR e iniciar os procedimentos de RCP segundo o protocolo imediatamente.

\section{Referências}

Aragão, E. S., Assis, \& Santos, E. (2017). Abordagem técnico-científica dos profissionais de enfermagem durante a assistência a uma parada cardiorrespiratória: uma revisão integrativa. International Nursing Congress Theme: Goodpracticesofnursingrepresentations Intheconstructionof Society

Aguiar, J. B. N., \& Andrade, E. G. S. (2018). Conhecimento da equipe de enfermagem sobre o protocolo de ressuscitação cardiorrespiratória no setor de emergência. Rev Inic Cient e Ext. 2018;1(Esp.4):334-41

Braga, R. M. N., Fonseca, A. L. E. A., Ramos, D. C. L., Gonçalves, R. P. F., \& Dias, O. V. (2018). Atuação da equipe de enfermagem no atendimento à vítima de parada cardiorrespiratória no ambiente intra-hospitalar. Rev. Aten. Saúde, 16(56), 101-107.

Bernoche C, Timerman S, Polastri TF, Giannetti NS, Siqueira AWS, Piscopo A et al. Atualização da Diretriz de Ressuscitação Cardiopulmonar e Cuidados de Emergência da Sociedade Brasileira de Cardiologia - 2019. Arq Bras Cardiol. 113(3):449-663

Cruz, L. L., Rêgo, M. G., \& Lima, É. C. (2018). O Enfermeiro Frente À Parada Cardiorrespiratória Em Ambiente Hospitalar: desafios do cotidiano.

Castanheira, J. S., Oliveira, S. G., Rocha, L. P., Neutzling, B. R. S., Cadaval, P. M., \& Leite, S. S. (2020). Assistência na parada cardiorrespiratória: estruturas do cuidado em saúde em uma unidade de internação hospitalar. Research, Society and Development, 9(9), e329997319, http://dx.doi.org/10.33448/rsdv9i9.7319

Espíndola, M. C. M., Espíndola, M. M. M., Moura, L. T. R., \& Lacerda, L. C. A. (2017). Parada Cardiorrespiratória: Conhecimento Dos Profissionais De Enfermagem Em Uma Unidade De Terapia Intensiva. Revenferm UFPE online, 11(7):2773-8.

Farias, V. E., Felini, K., Macedo, J. M., Mattos, \& Ribeiro, M. (2015). Sistematização Da Assistência De Enfermagem Diante Da Parada Cardiorespiratória (PCR). Revista Thêma et Scientia - Vol. 5, no 1E, jan/jun. - Edição Especial Enfermagem.

Gil, A. C. (2010). Como Elaborar Projetos de Pesquisa. Atlas.

Gonzalez, M. M., Timerman, S., Gianotto, O. R, Polastri, T. F., Canesin, M. F., Schimidt, A., et al. (2013). I Diretriz de Ressuscitação Cardiopulmonar e Cuidados Cardiovasculares de Emergência da Sociedade Brasileira de Cardiologia. 101(2).

Moura, L. T. R., Lacerda, L. C. A., Gonçalves, D. D. S., Andrade, R. B., \& Oliveira, Y. R. (2012). Assistência Ao Paciente Em Parada Cardiorrespiratória Em Unidade De Terapia Intensiva. Rev Rene.13(2):419-27.

Oliveira, G. F. S. M., Santos, L. G. E., Santos, M. A. S., Gusmão, C. M. P., \& Rocha, D. M (2021). Assistência de enfermagem em relação às diretrizes de atendimento a parada cardiorrespiratória. Ciências Biológicas e de Saúde Unit, 6(3), 21-30, maio

Prestes, J. N., \& Menetrier, J. V. (2017). Conhecimento da equipe de enfermagem de uma unidade de terapia intensiva adulta sobre a parada cardiorrespiratória. Biosaúde, 19(1)

Rocha, F. A. S., Oliveira, M. C. L., Cavalcante, R. B., Silva, P. C., \& Rates, H. F. (2012). Atuação Da Equipe De Enfermagem Frente À Parada Cardiorrespiratória Intrahospitalar. R. Enferm. Cent. O. Min. 2(1):141-150. 